\title{
LA REVISTA LA ENSEÑANZA PRIMARIA: UNA PUBLICACIÓN POR Y PARA PROFESORES. MÉXICO, I9OI-I9II
}

\section{The La Enseñanza Primaria magazine: a publishing by and for teachers, IOOI-I9II}

\author{
Rosalía Meníndez Martínez \\ Universidad Pedagógica Nacional, México \\ Correo-e: r_menindez@yahoo.com.mx \\ Recibido: 16 de noviembre de 2020 \\ Envío a informantes: 2I de noviembre de 2020 \\ Aceptación definitiva: I9 de diciembre de 2020
}

Resumen: En este artículo me enfocaré en el estudio de la revista La Enseñanza Primaria, publicación dirigida a los maestros empíricos, así como a los normalistas. Parto del supuesto de que esta revista incidió en la política educativa nacional, pues su labor cultural y pedagógica se expandió tanto en la capital como en otras entidades del país y del extranjero, a través de la publicación de artículos, conferencias, traducciones, clases y diversas comunicaciones. Sus autores difundieron nuevos planteamientos pedagógicos y educativos para el magisterio. A finales del siglo xix el gobierno de Porfirio Díaz favoreció la profesionalización de los maestros en las Escuelas Normales; en estos espacios se formaron los intelectuales educativos más influyentes del país, los cuales buscaron espacios para debatir, crear y difundir el pensamiento pedagógico moderno.

Me planteo las siguientes preguntas: ¿Las revistas periódicas representan un mecanismo de formación educativa para el magisterio? ¿Cuál era el objetivo de una revista de maestros y para maestros?

Palabras Clave: Porfiriato; magisterio; revistas periódicas; modernidad.

Aвstract: In this article I will focus on the study of the Primary Education Magazine, a publication aimed at empirical teachers as well as normalistas. I start from the assumption that this magazine had an impact on national educational policy, since its cultural and pedagogical work expanded both in the capital and in other entities of the 
country and abroad, through the publication of articles, conferences, translations, classes and various communications. Its authors disseminated new pedagogical and educational approaches for the teaching profession. At the end of the inth century, the government of Porfirio Díaz favored the professionalization of teachers in Normal schools, in these spaces the most influential educational intellectuals in the country were formed, which sought spaces to debate, create and disseminate modern pedagogical thought.

I ask myself the following questions: Do periodicals represent an educational training mechanism for teachers? What was the purpose of a magazine for teachers and for teachers?

KEY WORDs: Porfiriato; magisterium; periodic magazines; modernity.

\section{Introducción}

\lceil

OS PROFESORES QUE HABÍAN EGRESADO de las recién creadas Escuelas Normales, tanto de la ciudad de México (I886-I889) como de otros estados del país, buscaban espacios de expresión y de difusión de las ideas pedagógicas que habían recibido y asimilado en estas escuelas. Los normalistas sabían de la importancia de contar con una publicación, esto significaba tener un canal de difusión de este pensamiento pedagógico y a la vez un espacio de autoridad y poder. Por tanto, estas publicaciones estaban dirigidas principalmente al magisterio e incluían como principal destinatario a los profesores normalistas, los estudiantes y de una manera muy especial a los profesores empíricos que solo a través de estos materiales podían acceder a los nuevos conocimientos que en materia educativa se gestaban y avanzaban rápidamente tanto en el país como en el extranjero.

Gregorio Torres Quintero, profesor egresado de la Escuela Normal de la ciudad de México, encabezó a un grupo de normalistas a fin de introducirse en diversos espacios del ámbito educativo; sus objetivos contemplaban no solo la formación y actualización del magisterio fuera de las aulas, también pretendieron insertarse en los círculos de la política educativa. Este se convirtió en un objetivo ambicioso pero posible para este grupo que se fortalecía y avanzaba en sus propuestas para la educación.

Uno de los espacios colegiados de diálogo e intercambio de ideas fueron las asociaciones de profesores y sus respectivas publicaciones. Gregorio Torres Quintero y su grupo no fueron ajenos a esta tendencia y se dan a la tarea de fundar el Colegio de Profesores Normalistas de México y su revista, que llevará el nombre de La Enseñanza Primaria. Quintero se inició como jefe de redacción y más tarde se convirtió en el director de la revista. El profesor Celso Pineda ocupó el lugar de editor y por diez años se mantuvo a la cabeza de la publicación y en sus últimos años fungió como director efectivo. El consejo editorial estaba integrado en su totalidad por maestros normalistas. Entre los socios fundadores estaban los maestros Celso Pineda (editor), Luis de la Brena y Ponciano Rodríguez. Estos cuatro maestros normalistas, incluyendo a Quintero, mantuvieron una exitosa publicación que fue leída en México y otros países. Al poco tiempo se sumaron importantes colaboradores, destacan los maestros:

En el año de 1908 la revista La Enseñanza Primaria publicó una biografía de los miembros fundadores e integrantes del consejo editorial Celso Pineda, Ponciano Rodríguez, Luis de la Brena y Gregorio Torres Quintero. 
LA REVISTA LA ENSEÑANZA PRIMARIA: UNA PUBLICACIÓN

POR Y PARA PROFESORES. MÉXICO, I 90I-I9I I

ROSALÍA MENÍNDEZ MARTÍNEZ

Daniel Delgadillo, Julio S. Hernández, Toribio Velasco, José Juan Tablada. Como parte del cuerpo de redactores se encontraban: José María Bonilla, Lucio Tapia, Jesús Sánchez y José Juan Barroso. Y más tarde se agregan a esta lista los nombres de Antonio Santa María, Carlos Flores, Manuel Velázquez Andrade y Francisco Montes de Oca.

La revista comenzó con un pequeño grupo integrado por cuatro maestros. A los pocos años incluyeron nuevos cooperantes hasta llegar a tener dos administradores por la expansión que gozó la publicación, como lo fueron los maestros Bernabé Barrera y Leopoldo Pardavell.

Sin duda la revista comenzó con buen pronóstico. En su primer número del i de julio de I9or, el 78 por ciento de los autores fueron los miembros del consejo editorial y normalistas cercanos a Quintero. Esta situación experimentó algunos cambios para los siguientes años, con la entrada de nuevas plumas. El número y la diversidad de autores creció al paso del tiempo. Los extranjeros y las mujeres tendrán una presencia que convirtió a la revista en una publicación de vanguardia en temas educativos destinados al magisterio. Las mujeres que colaboraron fueron pocas, pero sus firmas eran altamente reconocidas en el ambiente educativo. La revista vivió una larga vida. Comenzó en rgor y concluyó sus ediciones en r9ıo, previo al levantamiento armado.

Pero ¿cuál era el objetivo de una revista de profesores y para profesores? Su editor el profesor Celso Pineda lo escribe y lo explica detalladamente en el «Preámbulo» que aparece en el primer número de la revista, y cito a continuación:

Permítanos el lector unas cuantas palabras por vía de prólogo ó como una explicación acerca de los fines de esta humilde publicación.

Cuando un periódico de la naturaleza del nuestro hace su aparición, unos, los indulgentes, suelen acogerlo bondadosamente, y aún á veces buscan y quizá hasta creen hallar algo que les instruya y les guíe en la penosa carrera á que se han consagrado; pero otros, y son los más, malquerientes y adversarios por sistema de todo aquel que tiene la noble osadía de lanzar sus opiniones á la publicidad, juzgan cuestión de orgullo, de vanidad y de pretensión lo que no es sino un intento sano y por demás laudable: el de colaborar en la magna obra de la enseñanza.

A éstos hacemos formal protesta de nuestra humildad, por que ninguna pretensión, ni vanidad, ni orgullo, pueden tener aquellos cuyos nombres no tienen ningún favorable precedente, pues, exceptuando a nuestro compañero el Sr. Gregorio Torres Quintero, que dirigió con bastante acierto una publicación pedagógica en Colima, los demás somos casi desconocidos y nuestros nombres no han conquistado por cierto ningún timbre glorioso.

En cuanto á los primeros, aquellos que identificarse quieran con nosotros, hacémosles sincero ofrecimiento de poner á su disposición todas nuestras pobres energías, sirviéndoles, si así puede decirse, de intérpretes de las ideas más recientes que en materia de educación los grandes pensadores escriben.

Es decir, que nos dirigimos á aquellos que por lo exiguo de su sueldo no pueden tener á su alcance obras de mérito pedagógico, casi siempre muy caras, y á cuya lectura ni se podríanentregar, pues casi siempre necesitan en sus horas de descanso buscar otra preocupación productiva.

A ellos, con quienes bien queremos hacer nuestra comunión de ideas ante el ara bendita del bien común, dedicamos esta publicación, que, lo repetimos no lleva otra pretensión que la de colaborar en la obra grandiosa de la enseñanza y por ende de la evolución de México. 
¿Nuestro programa? Es bien sencillo: Tratar todos aquellos asuntos que sobre todo en la enseñanza primaria tengan un interés de práctica metodológica, sin que nuestras ideas tengan el carácter jamás dogmático, sometiéndolas, al contrario, al criterio de todos los que quisieren tratarlas si disiente de nosotros; si bien, lo haremos notar desde luego, no daremos ningún valor á ninguna indicación que no traiga el doble sello de la seriedad y de la sensatez; en tal caso, es necesario decirlo, cada uno de nosotros es personalmente responsable de las opiniones que en sus artículos vertiere.

Trataremos también de todo aquello que se relacione con lo que pudiéramos llamar legislación escolar; y por último, tal vez señalemos algunas que nos parecen deficiencias en lo meramente administrativo.

Esto es todo. Saludamos, pues, por medio de estas líneas, á la prensa y á nuestros compañeros de la Nación entera no sin mostrarles cuan grande nuestro júbilo y nuestra satisfacción serán si algún día se llegaré á decir de nosotros: contribuyeron, aunque escasamente, al bien de la Nación por medio de LA ENSEÑANZA PRIMARIA.

Celso Pineda ${ }^{2}$.

El preámbulo presenta claramente los objetivos de esta publicación. Sus lectores, los maestros de primaria, tendrán con esta revista acceso al conocimiento de los nuevos saberes escolares. Los artículos versarán sobre temas de interés para un profesor. Podrá conocer nuevos métodos y los nuevos libros de texto que son escritos por los normalistas, nuevos materiales escolares como láminas, atlas, mapas, cromos, ejercicios, modelos de una clase, entre otros. Un aspecto muy importante fueron las metodologías aplicadas para las disciplinas. Los maestros también podrán conocer de temas administrativos, legislativos y laborales. Los artículos escritos por extranjeros serían otra de las novedades, a fin de presentar temas de vanguardia a nivel internacional; los editores se dieron a la tarea de realizar o conseguir traducciones de artículos y libros completos, esta fue otra de las novedades. Por tanto, todos los aspectos relativos a divulgar el nuevo pensamiento pedagógico y los asuntos que interesan al magisterio fueron presentados en esta publicación.

Las formas y los costos para adquirir la revista eran diversas. Para el año de I90I, un semestre tenía un costo de \$o.65; un año, de \$r.25, el pago debía ser por adelantado. Se establecían varias opciones para adquirirla, lo más importante era distribuirla.

Como, por ejemplo:

I. Giramos por semestre, cargando \$0.25 cs. por gastos de giro.

II. Los subscriptores, sin embargo, pueden pagar por anualidades.

III. Recomendamos que de preferencia se nos hagan los pagos en giros postales.

Si se envían estampillas postales, deben agregarse \$o.io cs.

IV. Acusamos recibo en todo caso, por tarjeta postal.

V. No se remiten obras sin previo envío de su importe á quien corresponda.

Por más de cuatro subscripciones descontamos el 20 por Ioo3.

La revista mantuvo una circulación nacional, lo cual puede conocerse a través de varios aspectos: la participación de autores de diversas entidades, la publicidad y anuncios específicos dirigidos al magisterio de todo el país, las subscripciones e incluso a las temáticas que se abordan en los artículos.

La Enseñanza Primaria, t. I, número I, I de julio de I9oI, p. 2.

Revista La Enseñanza Primaria, tomo V, i julio de 1905, n. $^{\circ}$ I, México. 
Su publicación era quincenal. Comenzó en i90i y concluyó en i9ıo. Se editaron 205 números en io años. El primer número incluía I6 de páginas, al paso del tiempo llegó a tener un máximo de 32 páginas, esto correspondió al número del I de noviembre de 1905. El promedio se mantuvo entre i8 y 20 páginas. El número de artículos también cambió, empezó con 9 y se llegó a un máximo de i6. El artículo más extenso que publicó la revista fue el titulado "¿Letra inclinada o perpendicular?»", con 24 páginas, para presentar un importante y necesario tema como era la escritura, incluyó dibujos e imágenes y una amplia y detallada explicación.

En sus inicios la revista no incluía portada, solo indicaba los siguientes datos: jefe de redacción, tomo, fecha y lugar y número. Para el año de 1903 la revista incluyó una portada muy adecuada cuyo simbolismo expresaba el objetivo y mensaje de una publicación para maestros que promovían artículos modernos y de vanguardia con los nuevos saberes científicos y pedagógicos; la imagen del encabezado muestra niños de clase media muy europeizados con elementos de la ciencia, las matemáticas, la geometría, un globo terráqueo, libros, una diosa del saber, todo vinculado a un conocimiento moderno. También se agrega un sumario que especifica el título y el autor de cada artículo. Y se incluyen los nombres del comité editorial. Para ı9ıo, año en que concluyó la vida editorial de la revista, la portada y el formato se habían transformado para dar paso a un ejemplar que refleja la evolución en todos sentidos del grupo editorial de Torres Quintero .

Se había logrado editar una revista moderna, pues atendía temas de actualidad, con un diseño atractivo, de calidad. La imprenta encargada de la edición fue en un principio la imprenta El Siglo Diez y Nueve, más tarde la imprenta La Mujer Mexicana y, una más, Tipografía de José del Castillo.

\section{Las publicaciones pedagógicas: espacios de divulgación de los profesores}

Sí bien los espacios institucionales fueron básicos para la formación de elites de conocimiento también existieron otros sitios en donde las comunidades académicas se expresaban, pero sobre todo creaban y debatían nuevas ideas; las revistas pedagógicas, los boletines, periódicos, semanarios y en general una amplia y vasta prensa pedagógica que se nutría de los trabajos de maestros, pedagogos, educadores, médicos, abogados, funcionarios del ramo educativo y en general poseedores de conocimientos y propuestas para mejorar la educación del país. El último tercio del siglo xIX se gestaron importantes cambios en la educación derivados de nuevas corrientes pedagógicas (Pestalozzi, Dewey, Spencer), así como la profesionalización del magisterio, y en donde la prensa educativa despuntó como producto de estos cambios en al ámbito pedagógico, dando como resultado la proliferación de publicaciones educativas.

La producción fue amplia, baste con mencionar solo algunas de estas publicaciones: La Enseñanza Primaria, La Enseñanza Normal, Boletín de Instrucción Pública, El Eco Pedagógico, El Escolar Mexicano, El Magisterio Nacional, El Magisterio, La Educación Contemporánea, La Enseñanza Moderna, La Enseñanza Objetiva, La Escuela Mexicana, La Escuela Moderna, Revista de Enseñanza Americana de Instrucción y Recreo dedicada a la Juventud y Anales de Higiene escolar. La actividad

4 Revista La Enseñanza Primaria, tomo V, I de noviembre, 1905, n. ${ }^{\circ} 9$. 
editorial era intensa, 24 estados de la república participaban con publicaciones. Al respecto, Amalia Nivón señala: «El Distrito Federal, Veracruz y Oaxaca son los lugares donde se concentra el $42 \%$ de la prensa pedagógica del país en los últimos diez años del siglo XIX» (2005, p. I2I). Además de estas publicaciones, las autoridades oficiales fundaron las revistas México Intelectual; Revista de Instrucción Pública Mexicana (1896-1902), llamada después Boletín de Instrucción Pública (1903-1913), y Boletín Bibliográfico Escolar; todos estos espacios editoriales que difundían materiales oficiales: decretos, programas y planes de estudios, libros de texto autorizados para las escuelas, reglamentos escolares, leyes, etc., pero también aparecían artículos de profesores y especialistas en educación tanto nacionales como extranjeros.

La prensa pedagógica destinada a los maestros de instrucción primaria y normal va ganando espacios y, por supuesto, lectores; con sus ediciones quincenales o mensuales se mantienen por varios años y en algunos casos por décadas, como fue el caso de la revista La Enseñanza Primaria. El subsecretario el ramo de Instrucción Pública y Bellas Artes, Ezequiel A. Chávez, señalaba en relación a las publicaciones escolares lo siguiente:

En la actualidad tres órdenes de publicaciones de diverso índole: a) las primeras y mas antiguas revistas de estudios especiales, tales como los de medicina, de Agricultura o la extinguida publicación llamada La Escuela de Artes y Oficios; b) las segundas, publicaciones de corto número de páginas dedicadas a la instrucción primaria, y útiles sobre todo para divulgar los principios de la metodología relativa. [...] Finalmente c) un tercer grupo de publicaciones escolares está constituido por aquellas que desean ser el fiel trasunto de los progresos del país y que reproducen todas las leyes vigentes en particular, así como los datos estadísticos y estudios pedagógicos que caracterizan la educación nacional en sus diversos grados y bajo sus múltiples fases. La única publicación que parcialmente responde a este desideratum es la revista de Instrucción Pública Mexicana, que fue organizada por la Secretaría de Justicia, que circula gratuitamente entre los profesores del país, y que bajo la dirección del autor de este estudio, ha publicado ya todas las leyes vigentes sobre el particular en el Distrito Federal, varios de los estados, y, año por año, los programas vigentes en las escuelas oficiales, para difundir a ese respecto los procedimientos y métodos adoptados. (Meneses, 1998, pp. 90I-902)

Aquí tenemos los tres modelos de publicaciones que circularon en el país a finales del siglo xix y primeras décadas del xx, y que expresaban los objetivos e intereses de diversos actores educativos: profesores normalistas, autoridades educativas y los intelectuales educativos. El punto de unión es la idea de expandir los avances de la pedagogía moderna y construir la escuela nueva.

En este ambiente intelectual y de modernización se enmarca el trabajo editorial de la revista La Enseñanza Primaria.

\section{Autores nacionales y extranjeros: un intercambio cultural entre México y otras naciones}

Gregorio Torres Quintero, como director, ejerció un férreo control sobre todos los artículos publicados, a fin de impulsar la línea de la revista, es decir, divulgar artículos vinculados al proceso de modernización de la educación mexicana. La nueva 
pedagogía, con sus métodos, prácticas, nuevos saberes y materiales escolares, debía ser prioritaria. Así como toda la información de orden administrativo, legislativo y laboral que los maestros debían conocer. Por tanto, había que alimentar la revista con estos temas.

Los socios fundadores y el profesor Daniel Delgadillo, amigo y compañero de Torres Quintero, publicaron el mayor número de artículos: Celso Pineda I2, Luis de la Brena I2, Gregorio Torres Quintero 36, Ponciano Rodríguez 8, Daniel Delgadillo ı. Del grupo normalista estaban Toribio Velasco con 4 artículos, Lucio Tapia con 2 y Jesús Sánchez con I.

Por su parte, los autores extranjeros inician sus contribuciones desde el primer número, con tres artículos de origen cubano. Rodolfo Menéndez, radicado en Mérida, Yucatán.

Entre 1904 yig05 se suman las plumas de destacados profesores normalistas como Daniel Delgadillo (ro artículos), Lucio Tapia (8), Toribio Velasco (7), José María Bonilla (5), José Juan Tablada (I) y Julio S. Hernández. Los otros colaboradores son profesores o intelectuales cuyas ideas estaban vinculadas a la pedagogía de la nueva escuela. Los temas atendidos se vinculaban con las asignatura del currículum, como matemáticas, física, geometría, biología, geografía, historia y civismo. La materia de lecciones de cosas eran tema prioritario, así como los métodos de lectura y escritura.

La revista promovió la inclusión de colaboradores de diferentes estados de la república, lo cual fue un punto a su favor, al tener profesores-lectores en todo el país, que necesitaban de artículos que les apoyaran en diferentes aspectos de su labor docente. Destacan los estados de Jalisco, Colima, Chihuahua, Yucatán, Campeche, Guanajuato, Veracruz, Puebla, Hidalgo, Estado de México, Sonora, Nuevo León, Sinaloa, Baja California, Nayarit y, por supuesto, la ciudad de México. También procuraron incluir artículos de autores que provienen de otras partes del mundo, a fin de tener una mirada internacional, se mantuvo un intercambio con el exterior en temas pedagógicos. Por ejemplo, se incluyeron artículos sobre la mujer que trabaja, la división del trabajo y sus ventajas y varias traducciones de artículos y libros completos de autores extranjeros.

La revista contó con artículos de mujeres, sus firmas era altamente reconocidas en el ambiente educativo. Destacan los nombres de Estefanía Castañeda, Dolores Correa Zapata, María Enriqueta, Laura Méndez de Cuenca. Y algunas menos conocidas como Altagracia Corona, María Martínez de los Ríos, Amalia M. Chacón, Ignacia Tenorio Hernández y Virginia Ramos. Los temas abordados por estas articulistas giraban en torno a la pedagogía, poemas, opiniones y disciplinas específicas.

Algunas traducciones de textos de mujeres fueron incluidas como los de Sarah Louise Arnold, Elodia Chiron y Gómez y la Sra. P. W. Cochrerís, que escribió Pedagogía de los trabajos de aguja, traducción presentada en varios números de la revista.

El proceso de internacionalización de la revista se muestra en los números publicados entre los años de 1904 a 1905. Se presentan 38 artículos de extranjeros de un total de 179 artículos de nacionales y 92 sin nombre, dando un total de 309 artículos publicados.

¿Pero quiénes son estos autores y de qué países eran? Tenemos la presencia de II países y 17 autores. Los países que tienen presencia son El Salvador, Ecuador, Cuba, Italia, Alemania, Rusia, Honduras, España, Venezuela, Argentina y Nicaragua. Los autores con mayor presencia corresponden a la América Latina. Se denota una buena 
relación de los profesores mexicanos con sus pares de lengua hispana. España y Cuba son los países que cuentan con un mayor número de colaboradores. En un segundo lugar, los ecuatorianos y rusos contribuyeron con artículos para la revista. Europa también ofreció una colaboración con la representación de 4 países (véase Cuadro I). Los temas más presentados publicados son cuento, moral, matemáticas e instrucción cívica.

Cuadro i. La Enseñanza Primaria (1904-1905). Autores por país

\begin{tabular}{|c|c|c|}
\hline Autor & País & Artículos \\
\hline Antonio Pons Campuzano & Ecuador & 4 \\
\hline Bonifacio Byrne & Cuba & I \\
\hline Cesare Lombroso & Italia & I \\
\hline $\begin{array}{l}\text { Christian Johann Heinrich } \\
\text { Heine }\end{array}$ & Alemania & I \\
\hline Ildefonso Estrada y Zena & Cuba & 2 \\
\hline Iván Serguéyevich Turguénev & Rusia & 2 \\
\hline J. R. Orcí & $\mathrm{s} / \mathrm{p}$ & 2 \\
\hline $\begin{array}{l}\text { J. Ray (traducido por Miguel } \\
\text { Rivera) }\end{array}$ & $\mathrm{s} / \mathrm{p}$ & II \\
\hline Jéronimo J. Reina & Honduras & I \\
\hline Joaquín Dicenta Benedicto & España & I \\
\hline José María Silva & El Salvador & I \\
\hline José Selgas & España & 2 \\
\hline Juan G. Russel & $\mathrm{s} / \mathrm{p}$ & I \\
\hline León Tolstói & Rusia & 2 \\
\hline Nicanor Bolet Peraza & Venezuela & I \\
\hline Pedro María Olive, de Olive & Español & I \\
\hline Rafael Obligado & Argentina & I \\
\hline Rodolfo Menéndez & Cuba & I \\
\hline Rosalino Carrera & Ecuador & I \\
\hline Rubén Darío & Nicaragua & I \\
\hline
\end{tabular}

Fuente: La Enseñanza Primaria, México, I de julio de 1904-Is de junio de 1905, vols. I-24. 
Para 1908-1909 la revista presentó cambios en su relación internacional. Son menos países, 8 en total. La diferencia es el cambio geográfico. La presencia de Europa es mucho mayor con una hegemonía de parte de Francia con is artículos publicados por diferentes autores, seguida de España con 6 y los Estados Unidos con 5, Inglaterra envía I artículo, y Argentina, Cuba, Venezuela y Ecuador mantienen sus vínculos con la revista. El caso de Francia es notorio y comprensible por el modelo educativo que México impulsó a finales del siglo XIX. El modelo pedagógico, con todo su planteamiento teórico, vienen de este país. Por ejemplo: libros escolares, mobiliario y materiales, ejercicios y lecciones, incluso vestimenta y juguetes. Por tanto, existe una estrecha relación de los normalistas con la pedagogía francesa. En los últimos años de la revista se fue consolidando el grupo de autores extranjeros con un total de 33 artículos de extranjeros frente a 34 mexicanos y 35 sin autor determinado y de 12 no se localiza información del autor, así que se desconoce si es mexicano o extranjero (ver Cuadro 2).

Cuadro 2. La Enseñanza Primaria. Autores-artículos extranjeros, 1908

\begin{tabular}{|c|c|c|}
\hline Autor & Número & Artículo \\
\hline $\begin{array}{l}\text { Dr. Augusto Bunge } \\
\text { (Argentina) }\end{array}$ & I9O8, n. ${ }^{\text {os }}$ I, 2 y 3 & $\begin{array}{c}\text { Educación de los atrasados } \\
\text { escolares }\end{array}$ \\
\hline $\begin{array}{l}\text { Sarah Louise Arnold } \\
\text { (Estados Unidos) }\end{array}$ & $1908,{ }^{\circ}{ }^{\circ}$ & Para dar una lección de cosas \\
\hline $\begin{array}{l}\text { Henry Hauser } \\
\text { (Francia) }\end{array}$ & I908, n. ${ }^{\circ} 3$ & $\begin{array}{c}\text { La escuela forestal } \\
\text { de Charlottemburgo }\end{array}$ \\
\hline $\begin{array}{l}\text { P. W. Caheris } \\
\text { (Francia) }\end{array}$ & $\begin{array}{c}\text { I908, n. }{ }^{\text {s }} 6,7,8,9, \text { Io, } \\
\text { II y I2 }\end{array}$ & $\begin{array}{l}\text { Pedagogía de los trabajos } \\
\text { de aguja }\end{array}$ \\
\hline $\begin{array}{c}\text { Conrado Gay Pollot } \\
\text { (Francia) }\end{array}$ & $\begin{array}{c}\text { I908, n. }{ }^{\text {os }} 7,8, \text { IO, II, I2 } \\
\text { y I3 }\end{array}$ & $\begin{array}{c}\text { Ejercicio de institución } \\
\text { y de lenguaje }\end{array}$ \\
\hline $\begin{array}{c}\text { J. Baldwin } \\
\text { (No encontrado) }\end{array}$ & I908, n. ${ }^{\circ} 8,9$ y го & Táctica Escolar \\
\hline $\begin{array}{l}\text { Ezequiel Bujanda } \\
\text { (Venezuela) }\end{array}$ & I908, n. ${ }^{\circ} 9$ & $\begin{array}{l}\text { Sobre las olas } \\
\text { (poema) }\end{array}$ \\
\hline $\begin{array}{c}\text { Sluys } \\
\text { (Escribió en i925 el libro } \\
\text { Cinematografía Escolar } \\
\text { (España-Argentina) }\end{array}$ & I908, n. ${ }^{\text {os }}$ IO y II & $\begin{array}{l}\text { Las fiestas escolares } \\
\text { Sugestiones para una } \\
\text { metodología del dibujo }\end{array}$ \\
\hline $\begin{array}{l}\text { L. C. Bon } \\
\text { (Francia) }\end{array}$ & I9O8, n. ${ }^{\circ} \mathrm{II}$ & $\begin{array}{l}\text { El uso de láminas } \\
\text { en la enseñanza }\end{array}$ \\
\hline $\begin{array}{c}\text { Frederick James Gould } \\
\text { (Inglaterra) }\end{array}$ & I909, n. ${ }^{\circ}$ I4 & El deber de ser útil \\
\hline
\end{tabular}

Fuente: Elaboración propia con datos de La Enseñanza Primaria, I908-1909. 
Las temáticas del extranjero, al igual que las nacionales, se centran fundamentalmente en los siguientes temas: historia, instrucción cívica, lenguaje (español), dibujo, lecciones de cosas, geografía, pedagogía, trabajos manuales, biología, moral práctica, gimnasia, matemáticas, higiene escolar, materiales escolares, poesía, geometría y cuentos. Existe una serie de temas varios centrados particularmente en legislación, disciplina, educación, escuelas, profesores.

Se realizaron varias traducciones del inglés, alemán, francés e incluso ruso, a fin de dar a conocer trabajos novedosos y sobre todo que se vincularan con las ideas del proyecto educativo porfiriano.

La idea de señalar el aspecto cuantitativo de los colaboradores nos permite tener una concepción amplia sobre el carácter, la complejidad y el alcance de una publicación de profesores que logró insertarse en una lógica de redes intelectuales que los lleva a posicionarse como una publicación de reconocimiento. Las redes que establecieron los profesores normalistas de la ciudad de México con los profesores e intelectuales interesados en temas educativos en América Latina y Europa se hacen visibles con este intercambio de conocimientos y saberes a través de la publicación de artículos de actualidad e innovación.

La revista procuró dar cabida a colaboradores de diversos estados del país. Sí bien la publicación se editaba en la ciudad de México, el objetivo era expandir la línea pedagógica e ideológica de la revista a los otros profesores de diversos estados del país. La iniciativa de incluir textos de autores extranjeros tenía por objetivo mostrar la mirada del exterior a fin de tener una revista actualizada y de vanguardia en temas pedagógicos.

\section{Nuevos temas para la revista}

La revista incorporó una diversidad de contenidos, desde traducciones de artículos o libros completos, adaptaciones, materiales inéditos, formas de dar una clase con las recomendaciones prácticas para la enseñanza de determinada lección, poemas, cuentos, noticias del ramo educativo y palabras de condolencia por la muerte de algún profesor, como fue el caso de Enrique C. Rébsamen y Alberto Estrella. También se incluyeron una serie de ejercicios y problemas, ya sea de matemáticas o geometría, para ser utilizados por los maestros en sus clases, noticias del Colegio de Profesores normalistas de la ciudad de México y guías metodológicas. En especial estas guías fueron ampliamente promovidas y demandadas por los normalistas. También se incluyeron las novedades acerca de los sistemas escolares de otros países como Alemania, Estados Unidos, Japón, Francia, Rusia y Suecia. Otro aspecto considerado por la publicación fueron las recomendaciones para la vida escolar y privada de los profesores. Se suman las notas biográficas, opiniones de la prensa sobre algún tema educativo o para elogiar algún libro publicado por los normalistas, decretos, legislación, nuevos nombramientos, novedades editoriales, temas de historia de la pedagogía, reseñas de libros y todo tema relativo a la educación primaria, por ejemplo, en relación a las traducciones que se presentaban en la revista, que no fueron pocas. Leticia Moreno señala que estas traducciones jugaron un papel difusor importante pues permitieron que un buen número de maestros tuvieran acceso a obras pedagógicas de actualidad, 
obras que bajo otras circunstancias estaban fuera del alcance de casi todos los profesores (Moreno, 2002).

Como podemos apreciar la revista incorporó una diversidad de asuntos. Sin embargo, no debe pensarse que era una especie de miscelánea, existía un objetivo claro y un eje que sostenía todos los artículos. El principal objetivo fue plantear una publicación que apoyara a los maestros en el aula, pero además buscaba ser un medio de formación y actualización para el magisterio. Su preocupación principal era atender los temas que interesaban y requerían los profesores de enseñanza primaria en un sentido amplio y a la vez complejo.

Algo importante para una revista de este tipo fue la inserción de dibujos, imágenes, pero sobre todo fotografías que en su mayoría eran de profesores.

Los temas que promovía la revista se vinculaban principalmente con las necesidades pedagógicas del profesor en el aula y en su entorno educativo (aula, escuela, padres de familia, autoridades escolares, legislación, entre otras). A partir de los título y contenido de los artículos publicados por la revista, presento la siguiente clasificación del Cuadro 3.

\section{Cuadro 3. Clasificación de los artículos}

\begin{tabular}{|c|c|}
\hline $\begin{array}{l}\text { I. Materias de los } \\
\text { curricula de educación } \\
\text { primaria y Normal }\end{array}$ & 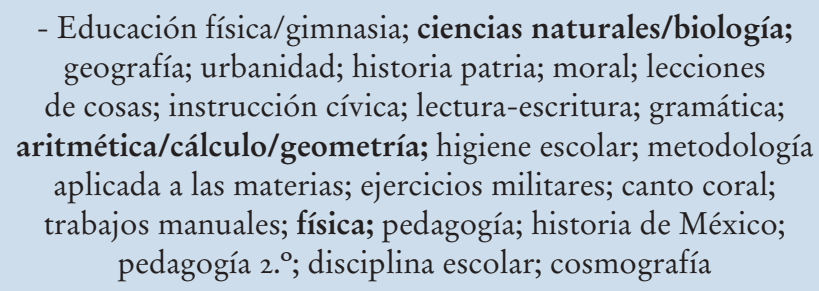 \\
\hline II. Nuevos métodos & $\begin{array}{c}\text { - Método onomatopéyico } \\
\text { - Nuevos métodos pedagógicos (comentarios y ejemplos) } \\
\text { - Objetivo } \\
\text { - Método intuitivo } \\
\text { - Métodos de la escritura-lectura, discusión en la academia } \\
\text { de profesores de Guadalajara }\end{array}$ \\
\hline III. Varios-pedagógicos & $\begin{array}{l}\text {-Poemas; cuentos; disciplina escolar; historia de la } \\
\text { educación para profesores; materiales escolares y materiales } \\
\text { didácticos (Atlas botánico de Luis Murillo, láminas, cuadros } \\
\text { murales, estampas, cromos); educación artística; conferencias } \\
\text { pedagógicas; juegos y ejercicios para clase/ejercicios } \\
\text { educativos; preparación de una clase/plan para una clase/ } \\
\text { modelo de una lección; la mujer en la enseñanza; academias } \\
\text { de metodología para señoritas; programas de estudio; } \\
\text { cuadros murales de historia patria; vida escolar (premios, } \\
\text { castigos, exámenes, vacaciones, trabajo en la escuela, } \\
\text { disciplina) }\end{array}$ \\
\hline
\end{tabular}




\begin{tabular}{|l|c|}
\hline IV. Magisterio & $\begin{array}{c}\text {-Deberes; discursos; escasez de maestros en Baja California } \\
\text { evolución del maestro y la enseñanza; condiciones laborales; } \\
\text { donativos para el magisterio; nuevos nombramientos; } \\
\text { opiniones de los maestros; convocatorias; disciplina; } \\
\text { premios; condolencias por la muerte de maestros; } \\
\text { información administrativa para profesores }\end{array}$ \\
\hline V. Libros de texto & -Libros de texto escritos por normalistas; promoción, \\
difusión de libros. Casas Bouret y Herrero Hermanos \\
(publicidad); importancia del libro de texto; comentarios \\
favorables a los libros de texto; listados de los libros de \\
texto aprobados; programas; cuestionarios; el uso de los \\
libros de texto en las escuelas; obras adaptadas para el \\
estado de Nuevo León; libros de consulta para los maestros \\
sinaloenses y de Baja California; todos los libros de texto \\
publicados por Gregorio Torres Quintero
\end{tabular}

Fuente: Elaboración propia con datos de la revista La Enseñanza Primaria, I9oI-I9Io.

La primera, y es la que sostiene el cuerpo de la revista, estaba centrada en la formación disciplinar, dando énfasis al aspecto científico con un perfil positivista. El núcleo de atención estaba en la ciencia: en las matemáticas, el cálculo, la geometría, la física, la biología/ciencias naturales y las lecciones de cosas. El interés por conocer cómo son las cosas, por acceder a un conocimiento útil y con ello desterrar la ignorancia es algo que interesaba y preocupaba a estos maestros normalistas de élite. Se conciben como los protagonistas del cambio educativo a través de la implementación de una nueva pedagogía basada en el conocimiento científico y en la atención y consideración del niño como un actor importante del proceso educativo; al lado del maestro, que es el poseedor del conocimiento, se desterrará la ignorancia y el atraso del país.

La escritura, lectura y gramática se sostienen también en este bloque. Sobra decir que son materias básicas del currículum. La novedad son los métodos de enseñanza-aprendizaje y los materiales escolares. Les siguen las disciplinas de los deberes integradas por la historia, la geografía, la instrucción cívica, la urbanidad y la moral. La atención al cuerpo fue muy valorada con las materias de higiene escolar, educación física/gimnasia y ejercicios militares; los espacios escolares, los materiales, uniformes, 
libros, horarios atendieron esta nueva asignatura. Y, por último, estaban las asignaturas para la formación artística como canto coral y dibujo.

La segunda línea se centra en los métodos para la enseñanza de las disciplinas escolares. Se dio una gran promoción al método creado por Gregorio Torres Quintero, el de lectoescritura (método onomatopéyico), otro método fue el objetivo o intuitivo, el cual encuentra un soporte importante con la asignatura de lecciones de cosas, materia a la cual la revista le dedicó un espacio en todos los números publicados (con un total de 6i artículos), es decir, era una asignatura que mostraba la nueva pedagogía. Algunos ejemplos, «Una esponja: lecciones de cosas». Torres Quintero fue el principal autor de estos artículos, publicó además los siguientes libros para esta materia: Lecturas intuitivas sobre vegetales útiles (Agricultura e industria) Escritas especialmente para servir de guía a los cuadros murales, impresos a varias tintas (1902); 38 Cuadros de lecciones de cosas sobre vegetales y animales (1904), y Lecturas intuitivas sobre vegetales útiles (1904).

La tercera, la conforman los libros de texto. Se dedicaron varios artículos a analizar y explicar su importancia (se incluyeron cuestionarios, métodos, ejercicios, metodologías), así como el uso que se debía tener en el aula con estos materiales escolares; algunos ejemplos: «Los libros de texto en la escuela primaria», «Los libros de texto y los programas», «El método en los libros de texto», «Los cuestionarios y los libros de texto». Otra de las vertientes de este tema es la amplia publicidad que se dio en tres puntos: el primero, la promoción por las casas editoriales como la Casa Bouret, la Editorial Herrero Hermanos, Sucesores; el segundo, los artículos titulados Opiniones de la prensa, la mayoría estaban enfocados a promocionar con sus elogios los libros de texto de los normalistas; $y$, el tercero, presentar Notas bibliográficas que cumplían la misma función de recomendar los libros de texto publicados por los normalistas. Los libros más publicitados fueron todos de los normalistas Gregorio Torres Quintero, Celso Pineda, Daniel Delgadillo, Lucio Tapia, Julio S. Hernández.

La cuarta área corresponde a los temas de y para el magisterio que son de interés en aspectos administrativos, legislativos, académicos y de vida cotidiana en la escuela. Este representa un punto de gran interés para el maestro que leía La Enseñanza Primaria. Los cambios políticos y educativos estaban impactando la vida de los profesores y requerían de nuevos conocimientos, saberes, aptitudes, pero también necesitaban información laboral y legislativa sobre sus puestos de trabajo, a fin de lograr insertarse en el nuevo escenario educativo. Los temas que destacan: deberes, la evolución del maestro y la enseñanza, las condiciones laborales, los nuevos nombramientos, las opiniones de los maestros, la disciplina en la escuela, la información administrativa para profesores, leyes, decretos, información oficial del Ministerio de Instrucción Pública.

Los artículos publicados en la revista representan un material tanto útil como necesario para que un profesor pudiera llevar a cabo su clase. Hay ejemplos realmente buenos y muy prácticos para este fin. Toribio Velasco escribe un artículo titulado «La preparación de clases». Pero no solo eso, también se le formaba y le enriquecía con artículos que ampliarán su visión e información sobre un determinado tema. Podemos ver que se abordan temas complejos, un ejemplo de moral, «Historias morales. El suicidio»; o muy concretos como, por ejemplo, gramática: «Palabras homófonas, ejercicios ortográficos». También los hay necesarios para transformar conductas y formar nuevos hábitos como es el caso de la higiene escolar, un ejemplo, «La inspec- 
ción médica y la higiene en la escuela». Y los muy necesarios por las nuevas tendencias modernizadoras, «Una clase de descripción de estampas».

Sí bien estas cuatro áreas se entretejían con las líneas editoriales de la revista, podemos señalar que existe un eje vertebral que sostiene y equilibra toda la publicación y este es la nueva pedagogía que conlleva toda una transformación en el ámbito educativo. Es una especie de torbellino que incluyó diversas esferas del ámbito escolar: libros de texto, materiales escolares, mobiliario, edificios, métodos, nuevos valores, entro otros. Un nuevo escenario educativo se mostraba al entrar el siglo xx, nuevos planteamientos para la enseñanza en las aulas y fuera de ellas.

\section{Consideraciones finales}

La revista La Enseñanza Primaria planteó como objetivo publicar artículos con un contenido útil para que los profesores contaran con materiales para impartir, mejorar sus clases, para acceder a conocimientos desconocidos, para actualizarse y para mantener una comunicación con otros profesores normalistas y empíricos. Fue una publicación de profesores y para profesores tanto mexicanos como extranjeros. Los artículos que incluía no se limitaron a contribuciones nacionales, sino que incluyeron artículos, traducciones de libros, conferencias, ejercicios. No solo fueron traducciones, también se incorporaron artículos de autores de habla hispana que trataban sobre temas de interés para el magisterio como cuentos, poemas, lecciones, ejercicios, narraciones literarias de tipo moral y ético, recomendaciones para dar una clase y cómo tratar a los alumnos. Una diversidad de temas que buscaban ofrecer al profesor un material actualizado, práctico y moderno. El objetivo se logró, las publicaciones periódicas para los profesores de primaria y normal fueron de las más extendidas y exitosas en todo el país y la revista La Enseñanza Primaria figuró como una de las publicaciones más importantes durante los años en que circuló. Los lectores de esta revista fueron fundamentalmente los profesores de educación primaria empíricos y normalistas, así como estudiantes normalistas que contaron con una revista actualizada y de vanguardia, que les ofrecía nuevos saberes, ideas, pero sobre todo que buscaba expandir el nuevo modelo educativo del Porfiriato, para un país que veía a la modernidad como su paradigma.

\section{Bibliografía}

Archivo Histórico de la Secretaría de Educación Pública. Fondo Secretaría de Estado y Despacho de Justicia e Instrucción Pública. Sección Antiguo Magisterio. Serie Personal Profesores. México.

Fondo Reservado y Fondo Histórico. Universidad Pedagógica Nacional. Ajusco. México.

Galván, L. E. (198I). Los maestros y la educación pública en México. Un estudio histórico. México: Nacional Impresora.

La Enseñanza Primaria, I90I-19II. México.

Meneses, E. (1998). Tendencias educativas oficiales en México I82I-I9II. México: Centro de Estudios Educativos. Universidad Iberoamericana. 
LA REVISTA LA ENSEÑANZA PRIMARIA: UNA PUBLICACIÓN

POR Y PARA PROFESORES. MÉXICO, I 9OI-I9I I

ROSALÍA MENÍNDEZ MARTÍNEZ

Morelos Torres, A. (2013). Publicaciones sobre educación en México en el siglo xIx. Revista de Historia de la Educación Latinoamericana, I5(20). Universidad Pedagógica y Tecnológica de Colombia, Tunja, Boyacá, Colombia.

Moreno, L. (20II). Los maestros intelectuales educativos I889-I9Io. En XI Congreso Nacional de Investigación Educativa. México.

Moreno Gutiérrez, I. L. (2002). La prensa pedagógica en el siglo xix. En L. E. Galván LAfarga (coord.), Diccionario de Historia de la Educación en México. México: conacyT-CIESAS.

Nivón, A. (2005). La participación de profesores de educación primaria en una reforma educativa: el caso de México (I890-1900). México: Universidad Pedagógica Nacional. 
